\title{
Comparison of temperature measurements of pacemaker leads in a 1.0T high field open MRI and a 1.5T classic cylindrical MRI: initial results
}

\author{
Sebastian A Seitz ${ }^{1}$, Julian J Ebner ${ }^{2}$, Gerriet Petry ${ }^{3}$, Evangelos Giannitsis², Olaf Dössel', Hugo A Katus², \\ Henning Steen ${ }^{2 *}$
}

From 2011 SCMR/Euro CMR Joint Scientific Sessions

Nice, France. 3-6 February 2011

\section{Introduction}

As of today, the use of MRI procedures on patients with implanted cardiac pacemakers is prohibited due to safety issues. The implants can interact with the RF fields of the MRI device. The most hazardous effect is heating at the tip of the lead, less dangerous are sensing errors and malfunctions of the devices, because they disappear completely after the procedure. The majority of the previous studies used classic cylindrical whole-body MRI systems. The influence of different alignments of the pacemaker/lead system and the RF fields were evaluated by comparing temperature changes occurring in a cylindrical device with the effects induced in a high field open MRI (HFO) system.

\section{Purpose}

Compare the influence of different RF field properties in cylindrical and open MRI systems in terms of induced heating in the vicinity of a pacemaker/lead system.

\section{Methods}

Two high energy MR-sequences with artificial ECG-triggering at $60 / \mathrm{min}$ were used on the $1.0 \mathrm{~T}$ HFO and the cylindrical system: 1 . T2-TSE (TR/TE $=177 / 38 \mathrm{~ms}$;TSEfactor $=16$; time $=58 \mathrm{~s}$; flip-angle $\left.=90^{\circ}\right) ; 2.3-\mathrm{D} \mathrm{bTFE}(\mathrm{TR} /$ $\mathrm{TE}=4.7 / 2.4 \mathrm{~ms} ; \mathrm{TFE}-$ factor $=6$; time $=382 \mathrm{~s} ;$ flip - angle $=70^{\circ}$; TFE-shot-duration $=34 \mathrm{~ms}$;TFE-shots $=532$ ). A conventional bipolar cardiac pacing lead (Medtronic Capsurefix Novus) was connected to a St. Jude Frontier II pacemaker. It was placed on a Plexiglas plate in a salinefilled Plexiglas phantom. Two configurations were tested

${ }^{2}$ University Heidelberg, Heidelberg, Germany

Full list of author information is available at the end of the article in both systems, one with the supporting plate of pacemaker and lead flat and one in a $90^{\circ}$ tilted configuration imitating the orientation in the regular and the opposite MRI system. Temperature measurements were captured with a fiber-optic measurement system.

\section{Results}

Highest temperature rise measured in the cylindrical system was $1.8^{\circ} \mathrm{C}$ with the supporting plane in a position that mimics the normal pacemaker orientation. The highest temperature increase in the open MRI $\left(0.6{ }^{\circ} \mathrm{C}\right)$ was observed in an upright configuration (see fig. 1). In the regular position, nearly no heating was induced in the lead (see fig. 2).

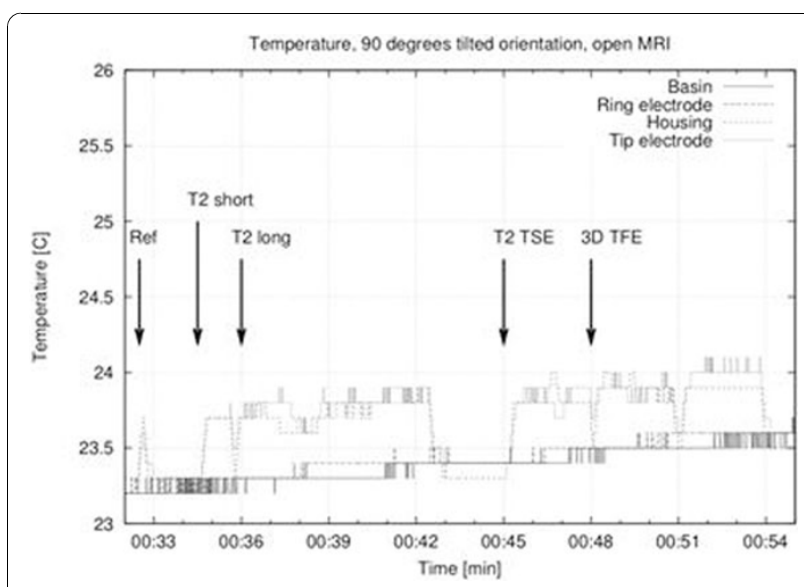

Figure 1 Temperature at four different spots while exposed to a series of MRI sequences in the open MRI system (90 degrees tilted). 


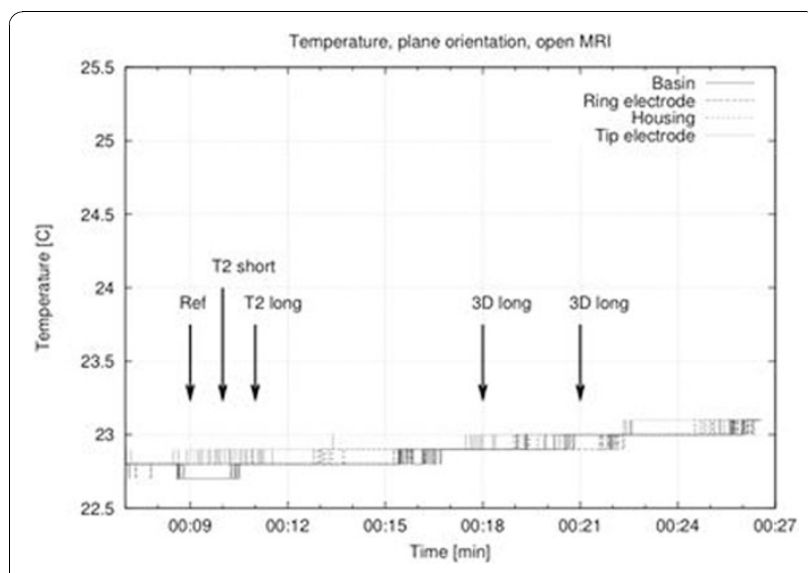

Figure 2 Temperature at four different spots while exposed to a series of MRI sequences in the open MRI system (flat orientation).

\section{Conclusions}

The comparative in-vitro measurements showed a significant influence of the RF field orientation. By tilting the pacemaker/lead system, effects observed in the cylindrical MRI system could be reproduced in the open MRI device. This study could confirm the advantageous properties of the open MRI system for patients with implanted cardiac pacemakers.

\section{Author details}

'Karlsruhe Institute of Technology (KIT), Karlsruhe, Germany. ${ }^{2}$ University Heidelberg, Heidelberg, Germany. ${ }^{3}$ Heidelberg Health System, Heidelberg, Germany.

Published: 2 February 2011
Submit your next manuscript to BioMed Central and take full advantage of:

- Convenient online submission

- Thorough peer review

- No space constraints or color figure charges

- Immediate publication on acceptance

- Inclusion in PubMed, CAS, Scopus and Google Scholar

- Research which is freely available for redistribution 